\title{
Engineering Educational Technology - Who Needs it?!
}

\author{
Ralph Harris \\ Department Mining, Metals and Materials \\ Engineering, McGill University \\ 3610 Universitry Street, \\ Montreal, QC H3A 2B2 \\ Ralph.Harris@McGill.CA
}

\author{
Cheryl Amundsen \\ Faculty of Education \\ Simon Fraser University \\ 8888 University Drive, \\ Burnaby, BC V5A $1 S 6$ \\ Cheryl_Amundsen@SFU.CA
}

\begin{abstract}
$\underline{\text { Abstract }}$
A lack of knowledge about teaching and learning that is quite common amongst engineering academics combined with a heavy set of professional demands, leads many teaching engineers to use outdated models of instruction or to simply repeat the teaching strategies that they themselves experienced. The present article seeks to inform engineering academics that there exist simple, yet powerful methods to design courses that will be effective for promoting learning and will be efficient in terms of preparation time. Students' opinions and desires regarding teaching and learning are also considered to provide a measure of the challenge associated with course design. In particular, the elements of learner centered course design are described with an emphasis on linking teaching and evaluation strategies to levels of learning and learning outcomes. Read along, slip into the role of a student for $a$ while and see what engineering educational technology can do for, or to, you and your teaching and learning skills.
\end{abstract}

\section{$\underline{\text { Introduction }}$}

Imagine yourself captured, inescapably imprisoned and told that your options are only (i) to be blown up at midnight or (ii) to press a button before midnight thereby saving another captured colleague in a similar predicament but be blown up immediately upon pressing the button. Such is the nature of a dilemma; it is a situation in which there are no attractive options.

The situation of professors in res earch universities has a parallel in that it is a dilemma whether to focus on research at the expense of teaching or to focus on teaching at the expense of research. Of course, there are those academics who think they can do both well, but this is not generally supported by the anecdotal reports of the students.

The underlying premise of this article is that there exist general design principles, which can be used to assist in the preparation and delivery of teaching so that the learning is improved. It is also an unsupported assertion of this article that such general design principles can also be used in the preparation and delivery of research, but the reader is left to explore this idea on their own.

The rhetorical title of this manuscript was chosen to attract readers' attention by asking a seemingly obvious question or by offering to provide guidance to stressed academics who need to strike a balance between the demands of research and teaching. It was also chosen to pray on engineering academics' tendency to want to use technology in their teaching, i.e., we wished to exploit the allure of hardware, toys or gadgets.

However it will be seen that within the theme of this paper, the use of hardware in education is a peripheral issue and that its use should be guided by instructional principles. It will also be seen that there is not much that is not obvious in what follows. However, each time the authors present this work, the engineering academics in the audience speak of some 'enlightenment' or simply a 'clarification' that they say is helpful with respect to the challenge of their teaching. Cheryl and I have seen that such insight eventually leads to better student learning. It has been helpful that the main author is firstly an engineer who has reflected extensively on teaching and learning and, as a result, is better able to 'connect' with an engineering audience than someone who is foremost, 
an education specialist and who is more often likely to be presenting work like the present.

It has als o become clear to us that despite the fact that the thinking presented in this paper has been part of the Educational literature for over 30 years, many engineering faculty are not familiar with it.

\section{$\underline{\text { Reflection }}$}

A powerful, but sometimes luxurious activity in an ever increasingly hectic professional academic life is taking the time to reflect. To this end, you are asked right at this moment to stop reading and reflect on the reasons you are reading this paper.............

If such a request immediately prompts you to want to stop reading altogether! you may want to ask yourself why it did - the intent here is to be helpful and your reaction may help you understand something of your relationship with teaching and learning.

If you remain interested in going-with-the-flow, do any of your reasons match the following?

- You are interested in the subject as suggested by the title.

- You are interested in what Cheryl and I have to say.

- You desire to become a better teacher and imagine continuing might be helpful.

- You want to see how to improve learning.

- You know someone else expects you to read this.

- You are trapped somewhere with nothing else to read.

Or are there other reasons, not immediately obvious.

The specific purpose of such purposefully guided reflection is to start the process of discovering one's own opinion in explicit terms. It is not until we express our thoughts out loud that we discover the extent of our mastery of a subject. As engineering academics we consistently have to be explicit about our research. As a result we have a very good sense of our expertise and are highly capable of being very efficient in the design and practice of our discipline. However, we are also required to be teachers and by and large, there is very little opportunity for us to be explicit about what we actually do as teachers.

If you persevere though this article and engage in the mental activities that Cheryl and I encourage along the way, you will have started the process of being explicit about teaching. Through the reflection you will engage in, you will have started the process of being able to promote better learning.

Please go one small step further. Take a pencil and write in the margin the reason you are reading this. Don't be shy, go ahead and write it down. It's not that we don't trust you, it's just so you do not have to rely on your memory when you get to the end of the article and we come back to this point.

Further, please reflect in your present role of receiver rather than giver of knowledge/learning by asking yourself: 'What are some of the assumptions that we make about our students?' Once you have given this a moment's pondering, you can turn to the references and get a hint [1].

\section{Outcomes}

Some of the principles that a reader can take away from this article are:

- Learning is a process.

- Teaching is about facilitating this process.

- 'Course-Design' is like any and all 'Design'.

- Using a Course Design Strategy lessens the dilemma described in the opening paragraph of this paper.

The bonus outcome is Improved Teaching and Learning when these principles are incorporated into teaching and its design.

\section{Theme}

Considering what you have read so far, what technology do you think is to be the focus of this article? Again, pause and respond to this explicit question in writing in the margin. We are not being rhetorical - we actually want you to know what you are thinking, or perhaps not thinking!

To help you expand on your prediction of the technology to be considered here, a small lecture follows below... "Patents, such as Post IT Notes, the Jarvic Heart Valves or the Magnola Process for Magnesium Production can be divided into the categories: Apparatus Patents or Process Patents. All are items of intellectual property, but unlike the patents protecting the physical objects, the notes and the valves, which are hardware, the patent for the Magnola Process protects an algorithm, which is software, for the transformation of earth bound minerals into useful metal." 
The Magnola Process is but one way of effecting such a transformation but, since it can be defined, made explicit and protected, it satisfies the definition of being a technology and for that matter it can be protected. By analogy, there are many means to effect the transformation of a student from a state of ignorance to a state of learnedness. If a process for such a transformation of a student is elaborated, made explicit and followed, by definition a technology has been defined and used.

Thus, the focus of this article is the technology of teaching and, like the method for producing magnesium, it is in the form of a process that we commonly call course design. Were you close with your prediction?

\section{'The Beef'}

To start the present lesson on course design, it is necessary to make explicit the way that we wish to use various words. One of the key words used in teaching is the verb 'to know'. The meaning we ascribe to the verb 'to know' is to be aware that you are in possession of a piece of information. It is a reality of human communication that as a 'teacher', you have no control beyond putting out the information; it is up to the audience (the students) to become aware of having the information (knowing - type 1 learning), of understanding it (comprehending - type 2 learning) and using it (applying - type 3 learning). Bloom [2] pursued such a breaking down the process of learning into these components and published his taxonomy of cognitive learning in 1956, almost 50 years ago! Figure 1 presents a schematic of Bloom's Taxonomy of Cognitive Learning, which is an orderly classification of the components of learning according to their relationships.

It can be seen that beyond the three types of learning mentioned above, Bloom included Analysis, Synthesis and Evaluation. A good way to understand Bloom's classification of the relationships between these components of learning is to consider a simple example. Again, you are asked to reflect. Consider the following levels of learning when you:

1. Know white is a colour (Knowing)

2. Understand that it is a light colour (Comprehension)

3. Apply white paint to a room to lighten it (Application)

4. Compare it to a dark room (Analysis)

5. Mix and prepare light colours other than white for variety (Synthesis)

6. Measure peoples' response to your colour scheme and improve it, if required (Evaluation).

Given that we want you to engage in all six levels of learning while reading this, reflect on what strategies might we employ to have you engage (learn) at each of these levels, i.e.: what do you think that we might have you do right now to have you know, understand, apply, analyze, synthesize and evaluate Bloom's taxonomy? This is not a rhetorical question either; make notes in the margin! When done, look at Reference [3] to see our suggestion..............

\section{Application}

To bring all this together effectively and efficiently requires something we are calling here 'Teaching Technology'. One example of such technology was practiced and preached by McGill's Center for University Teaching and Learning (CUTL - recently disbanded), in their annual Course Design and Teaching Workshop (CDTW), which is now offered through McGill's Teaching and Learning Services (a working title). The underlying principle of the CDTW is that benefits accrue to student-learning from a shift in paradigms, that is a shift from instructor-centered education to student-centered education.

Being guided by such a principle leads me to ask you

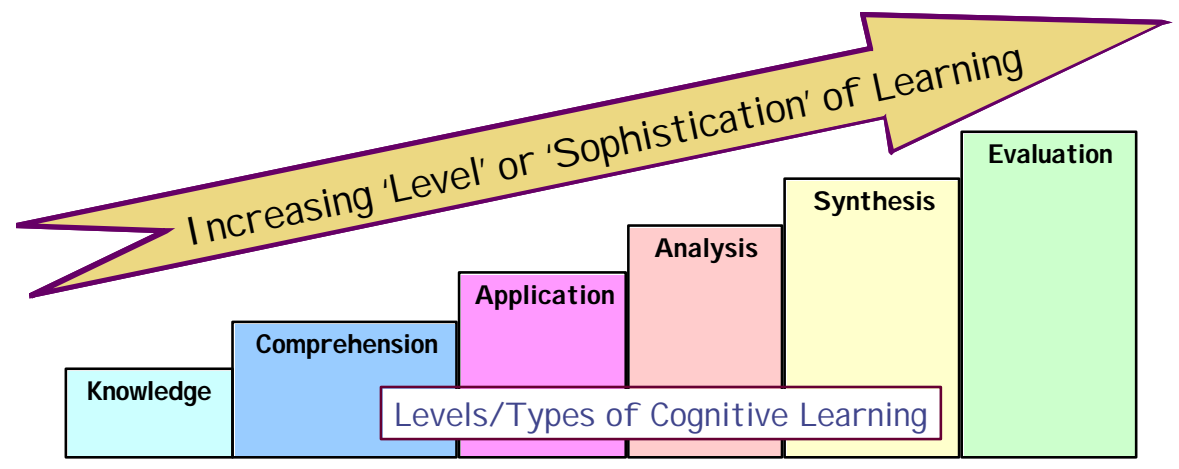

Figure 1 - Classification of Learning - Bloom's Taxonomy [2] 
to engage in active learning while you are reading this, rather than hoping that we are rhetorically masterful enough to sweep you away with our words.

In essence, we replace effort on our part with activity on your part. At first this might seem to be a cop out, but if you reflect again, you might see that in order to have you learn the things that we have think are valuable for you, we accept the limitation of our own skills as a charismatic writer and therefore do not place the supreme effort on being teachers. Rather, we use your willingness to learn from us, that is, focus on your natural tendency to be a student and as a result, end up with you following our simple instructions that are part of a process designed to get you exactly where we think you may benefit by going.

By analogy, Magnola's process (technology) was designed to produce magnesium. CUTL's process for designing a course was also created for a specific purpose, to produce student-learning.

\section{Elements of Course Design}

A semantic challenge facing the engineering academic is that we are charged with designing design courses yet we are seldom taught about the elements of a course design. The previous sentence was based on a strategy designed to introduce you to the scope of the difficulty and to start the process of having you engage in developing your own taxonomy, which could otherwise be called learning.

My choice of words for the first sentence and the way we put the words together was a strategy on our part to provide a learning outcome or goal for you. We cannot say whether you recognize this as a learning goal for yourself (i.e., to develop your own taxonomy); or whether our strategy has worked.

However, if we were face to face and we were using the same strategy, we could see by your reactions, or determine by quizzing you, the extent of the impact of the strategy and if necessary, have another run at it. Such is the power of face-to-face teaching, which is in essence just another strategy.

The astute reader will notice that we have brought two more ideas/concepts into our design in the first sentence, those of strategy and evaluation of learning and with these, the picture of the CUTL Course Design Process can be completed, Figure 2.

In the CUTL course design process:
- Concept mapping creates a graphical representation of the course knowledge and relationships within it.

- Learning outcomes are explicit statements about what will be known, understood, applied, analyzed, synthesized and evaluated by the students at the end of the course.

- $\quad$ Strategies are purposeful interventions on the part of the instructor to facilitate participants' journey to the outcomes.

- Evaluation is purposeful activity to measure the extent of mastery by the student. It is NOT grading and it is not evaluation in the sense that Bloom uses the word, however, for the instructor, it involves the highest levels of activity vis a vis the instruction per se.

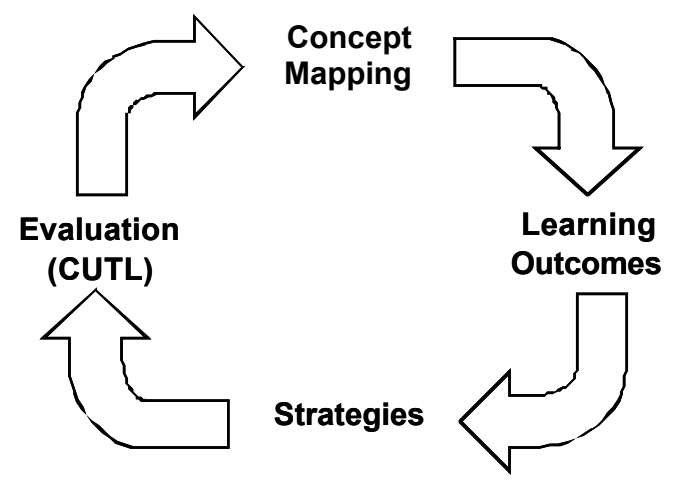

Figure 2 CUTL Course Design Process

We hope that your engagement in active learning since reading the first paragraph enables you to begin abstracting the design of this article for yourself, i.e., particular strategies have been purposefully selected and used to promote particular insights on the part of the reader. Figure 3 is included to drive home this point.

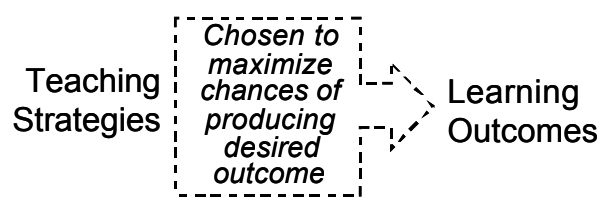

Figure 3 Selecting Strategies when Designing the
Course

A situation we have encountered when we were first exposed to the CUTL CDTW and when we talk to our engineering colleagues is that at first contact, engineering academics are often not aware of the vast range of strategies that exist. Additionally, they are often unaware of the strategies that they may already 
use implicitly, if not explicitly. Indeed, it is a purpose of this article to have you become aware of the strategies that you may already use, and evaluate some of them to see the extent to which they are beneficial for learning rather than just being a way of teaching. Table I lists some of the activities (strategies) employed by engineering academics sorted by Bloom's levels of cognitive learning.

Table I Various Teaching Strategies sorted by Bloom's Levels of Cognitive Learning

\begin{tabular}{|c|c|}
\hline $\begin{array}{l}\text { Bloom's Level } \\
\text { of Learning }\end{array}$ & Various Teaching Strategies \\
\hline Knowledge & $\begin{array}{l}\text { Lecturing (Verbal presentation, Direct } \\
\text { instruction); Modeling; Read text; } \\
\text { Films, videos; External resource use; } \\
\text { Entertainment; Act out or read a Play; } \\
\text { Book Talks; Discovery Learning; Data } \\
\text { Disk; Read aloud; Student web search } \\
\text { for specific information }\end{array}$ \\
\hline Comprehension & $\begin{array}{l}\text { Questions from teacher; Convergent } \\
\text { questions; Information searches; } \\
\text { Database searches and queries; Create } \\
\text { personal involvement; Justify (real } \\
\text { world applications); Instructor } \\
\text { Enthusiasm; Read newspaper each } \\
\text { morning; Hands on applications; } \\
\text { Closure at end of class; Graphic } \\
\text { Organizers, Concept Webs, etc.; Pre- } \\
\text { reading strategies; Reflection }\end{array}$ \\
\hline Application & $\begin{array}{l}\text { Questions from students; Assignments, } \\
\text { problem sets; Journals; Skill training } \\
\text { (drills); Papers; Cooperative Learning; } \\
\text { Jigsaw; Numbered Heads; Pair-Share; } \\
\text { Quiz Game; Classroom Assessment }\end{array}$ \\
\hline Analysis & $\begin{array}{l}\text { Group exercises; Tests; Feedback from } \\
\text { teacher; Field Trip; Questions: } \\
\text { Predictive; Hypothesize; Test Review }\end{array}$ \\
\hline Synthesis & $\begin{array}{l}\text { Simulations; Projects; Presentations; } \\
\text { Debate; Group problem solving; Poster } \\
\text { to represent ideas; Debate; Questions: } \\
\text { Divergent; Research Paper; Student } \\
\text { Constructed Object; Unfinished } \\
\text { sentences; Student mini lectures; Video } \\
\text { produced by students }\end{array}$ \\
\hline Evaluation & $\begin{array}{l}\text { Evaluate information; Critique Peer } \\
\text { work; Application of concepts to } \\
\text { personal life; Peer editing of written } \\
\text { work }\end{array}$ \\
\hline
\end{tabular}

Figure 4 presents a quiz for you to complete before finishing the article. Simply check-off against each strategy, the levels of learning you feel that the particular strategy addresses well. When you are done with that, we will go over some results from a student survey about what students think about relationships between strategies and learning and you will be done.

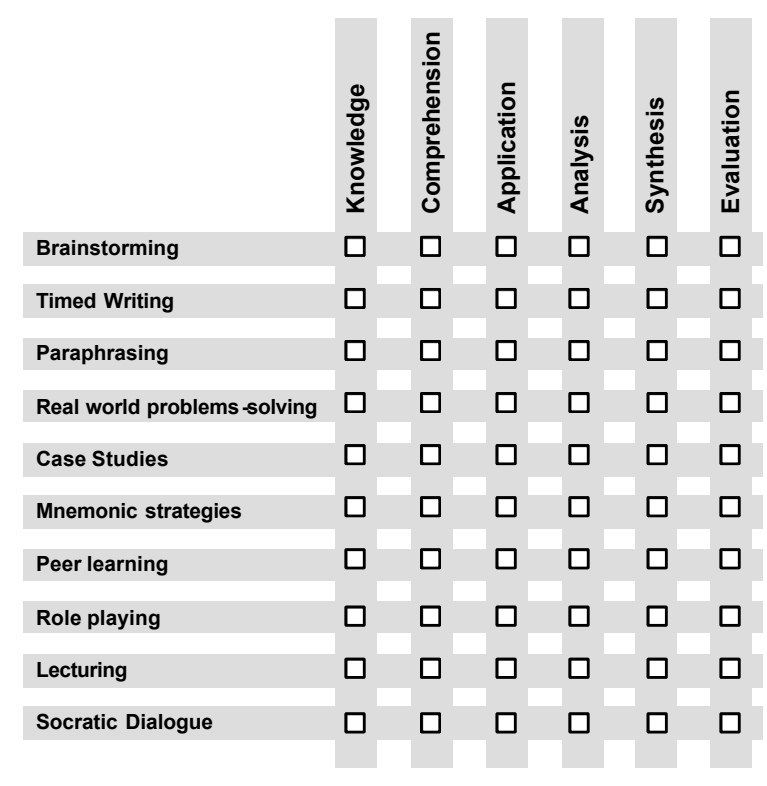

Figure 4 Quiz- 'self-evaluation' of your mastery of this article. Place a check in the box for the level of learning each strategy addresses well.

\section{$\underline{\text { Students' Perspectives }}$}

A recent survey of engineering students at McGill University [4] examined among other things, the teaching strategies that students said promoted learning. The responses of the students were categorized under the seven labels: DEMOnstrations; visual AIDS; LINKing to real life problems; prof's COMmunications; example PROBlems; explantions beyond GENeral readings; $\underline{\mathbf{R E V}}$ iew course content.

Figure 5 shows that though it was found that the impact of these strategies varied by the year of the student responding, the ranking of these strategies followed the order listed above.

Another component of the survey asked students which strategies that they would like to see used by their instructors. Interestingly the ranking is in a different order simply by total number of responses, but also, the ranking would change significantly if it was broken out by year of the student responding, see Figure 6.

The point to be taken here is that as students progress through their studies, their desires change. To help you think about what is going on inside students' 
heads these days, try a second quiz, Figure 6, in which you rank the levels of learning of the strategies as desired by the students.

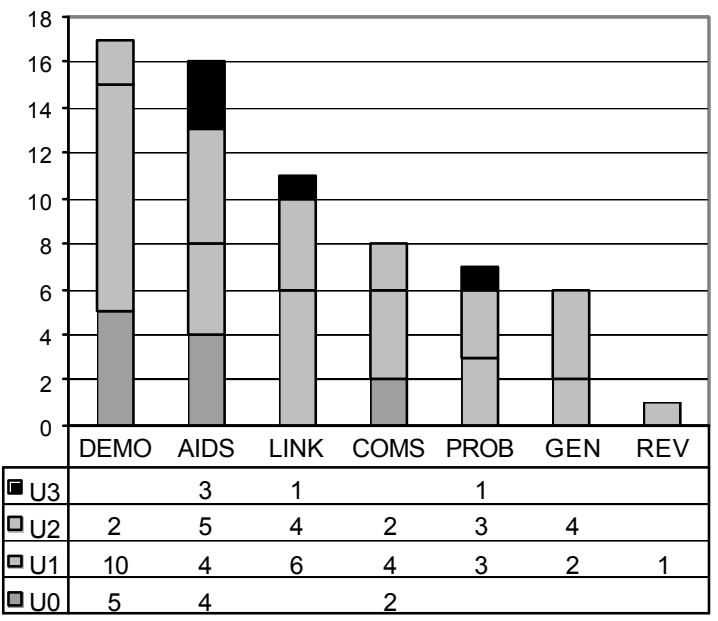

Figure 5 Students' ranking of strategies they feel worked to promote learning, broken down by year of student, after [4].

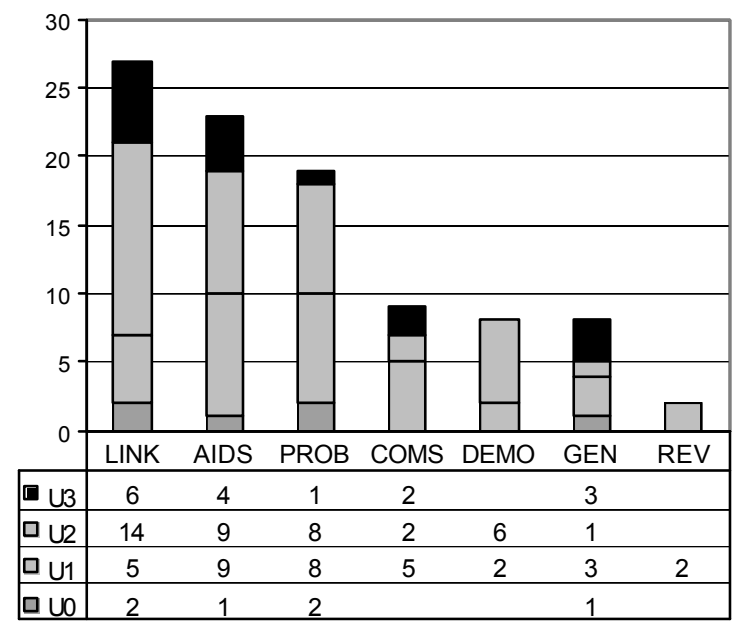

Figure 6 Students' ranking of strategies they would like to see used in teaching, broken down by year of student, after [4].

To expect such change as students progress is obvious, but it introduces yet another challenge for engineering academics whom it seems not only seldom reflect about how they are going to design a course but also have undertaken little if any research on learning per se and their students in particular.

Stepping back, it can be seen that for many courses the process of course design is one based on 'projection', i.e., designing a course based on the idea that students are like oneself. The consequence of such a misconception, perhaps even ignorance - this is what we would call it if our students undertook their assignments with such a low level of preparation, is that often engineering academics, even those who want to do a good job but do not know how and do not get the help to do so from their institutions, design their courses based on what they found worked for themselves, i.e., they follow a model that they liked or the model of an instructor that they admired.

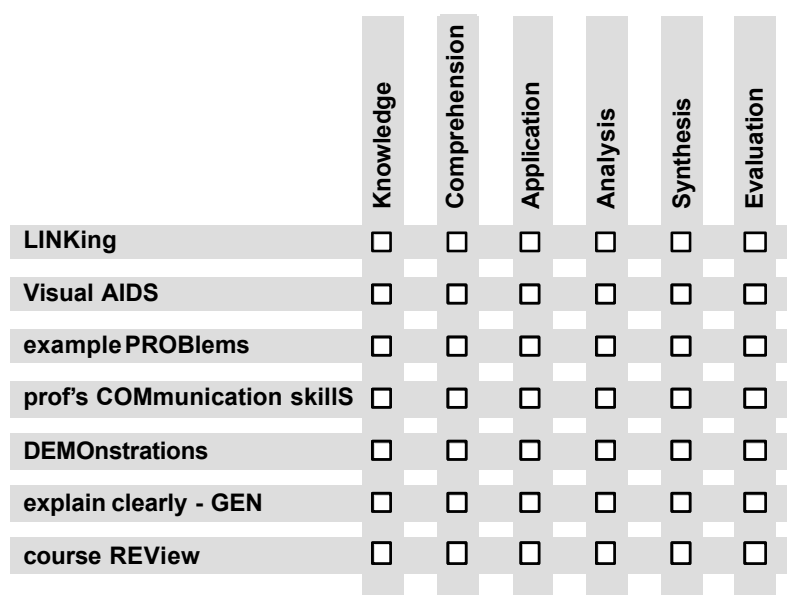

Figure 7 Quiz- What levels of learning do students desire? Place a check in the box for the level of learning each strategy addresses well.

Though such a strategy is not unsound, it misses the reality of the situation that engineering academics face; the world and its expectations have moved on since they were students and the students have moved on. Looking back to the good-old-days is a somewhat enjoyable past time in the staff lounge, but a rather weak strategy in the class room.

\section{$\underline{\text { Conclusions }}$}

Figure 8 presents a schematic of the design of this paper. It was our intent to share with you how we designed this text about how to design a paper about designing a course. The reason for this was that we wanted you to see the purposeful use of strategies chosen with a particular learning outcome in mind. It would be our hope that you might pause to ponder and, as a result, abstract some of the lessons imbedded in this article and hence engage in the process of learning something at Bloom's higher levels rather than just knowing and understanding some things at the lower levels as a result of simply reading this. It is accepted that the higher levels of learning are more readily attained when learning is active and our instructions to you in this article were an attempt to have you participate actively as you read along. 
We close with a set of rhetorical questions - no need for you to answer them, unless you want to. First, we return to the title of the article, Engineering Educational Technology - Who needs it?!. Perhaps it would be better to ask, who can afford to not use it given the demands on our lives? However, these questions beg other questions, for example: to what extent are engineering academics implicitly, or better still, explicitly using this technology (the course design process) already? Like the students, is there a difference between the ranks, or perhaps between the disciplines?

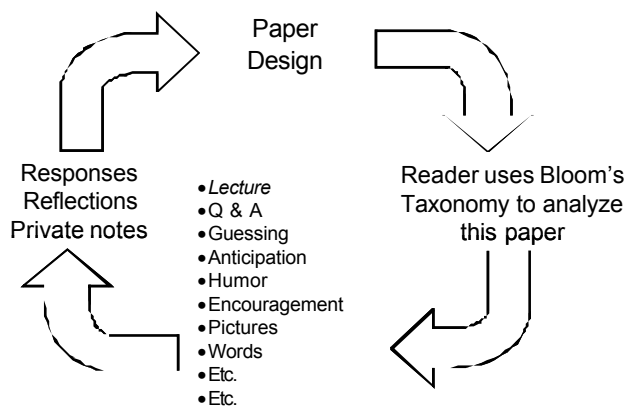

Figure 8 Concept map for the design of this article.

At the personal level, if you are one of the many well meaning, but regrettably ignorant engineering academics, are you doing to your student what was done to you or what you would have liked to have been done to you? An accurate and honest answer to this question might be quite difficult to come by, since by implication, the realization that such is the sum total of your design may provoke strong feelings of shortcomings.

However, this was not the purpose of this article but rather to provide encouragement to start the process of improving teaching and learning. In particular, the central ideas of this talk in explicit terms are:

1. Instructors need to be explicit (at least to themselves) about what the students should have learned/done by the end of the course/lecture/presentation.

2. Instructors use an array of strategies selected to most efficiently promote the explicitly specified learning(s).
These are two of the four components of CUTL's course design process something that is universally applicable and hence obvious once you think about it and it's FREE!! Also, it encourages the paradigm shift from instructor-centered education to studentcentered learning. Other impacts of the CUTL CDTW can be seen in the recent book written by a group of individuals associated, over the years, with CUTL and the course design workshop. [5].

\section{Epilogue}

As we promised, look at the note you wrote in the margin about the reason you were reading this paper and ask yourself:

"Did I get what I expected?"

"Was it worth the time I invested here?"

And remember, your students/audiences do this evaluation to some extent at the end of every class!

\section{References}

1 Example assumption about students: 'Students will bring something to write with'.

2 Bloom, B.S. (Ed.) (1956) Taxonomy of educational objectives: The classification of educational goals: Handbook I, cognitive domain. New York; Toronto: Longmans, Green.

3 Be explicit by writing notes and/or questions, even to yourself; for example: Can I see myself using Bloom 's Taxonomy in my own teaching? Such activity/reflection/evaluation implies a degree of mastery at all the levels of Bloom's taxonomy.

4 Kirk, A., Belisle, M. and McAlpine, L., 'Successful Strategies for Learning in Engineering', http://www.education.mcgill.ca/learning_engineer ing/report/rep1.html, Consulted April, 2004.

5 Saroyan, A. and Amundsen, C. (Eds.) (2004). 'Rethinking Teaching in Higher Education: From a Course Design Workshop to a Faculty Development Framework', Stylus Publishing, Sterling, VA, 2004. 